\title{
Implications of Changing National Cholesterol Education Program Goals for the Treatment and Control of Hypercholesterolemia
}

\author{
Stephen D. Persell, MD, MPH, ${ }^{7}$ Donald M. Lloyd-Jones, MD, ScM, ${ }^{2}$ David W. Baker, MD, MPH \\ 'Division of General Internal Medicine, Department of Medicine, and the Department of Preventive Medicine, Feinberg School of \\ Medicine, Northwestern University, Chicago, IL, USA; ${ }^{2}$ Division of Cardiology, Department of Medicine, and the Department of Preventive \\ Medicine, Feinberg School of Medicine, Northwestern University, Chicago, IL, USA.
}

\begin{abstract}
BACKGROUND: Modifications to the National Cholesterol Education Program (NCEP) guidelines lowered optional low-density lipoprotein cholesterol (LDL-C) treatment goals.
\end{abstract}

OBJECTIVE: We evaluated the implications of widely adopting these optional goals in clinical practice.

DESIGN AND PARTICIPANTS: We performed a cross-sectional study using 1999 to 2002 data from 3,281 U.S. adults aged 20 to 79 years participating the National Health and Nutrition Examination Survey.

MEASUREMENTS: The primary outcomes were the proportions of adults whose fasting LDL-C levels exceeded NCEP recommended and optional targets from 2001 and 2004. We used survey weights to estimate the size of the U.S. population exceeding targets. We examined outcomes for 4 coronary disease risk subgroups described by the NCEP.

RESULTS: Low-density lipoprotein cholesterol values exceeded 2001 NCEP goals for $30.0 \%$ of adults, and $35.8 \%$ had levels above optional 2004 goals. An estimated 24,900,000 individuals (14.2\%) exceeded 2001 thresholds for drug therapy, 46,200,000 (26.3\%) exceeded optional 2001 thresholds for drug therapy, and 56,500,000 (32.2\%) were above the optional 2004 thresholds for drug therapy. For lower, moderate, moderately high, and high-risk groups, $13.4 \%, 44.2 \%, 58.8 \%$, and $71.8 \%$, respectively, exceeded 2001 NCEP goals; $13.4 \%, 15.7 \%$, $87.4 \%$, and $96.0 \%$ of these groups exceeded optional 2004 thresholds for drug therapy.

CONCLUSIONS: In 1999 to 2002, LDL-C levels commonly exceeded 2001 NCEP goals, especially for moderately high and high-risk individuals, and cholesterol-lowering medications were underused. Optional goals promulgated by the NCEP in 2001 and 2004 moderately increased the number of adults with LDL-C above their goal, and greatly increased the number of low, moderately high, and high-risk adults who exceeded LDL-C thresholds, for cholesterol-lowering medication.

KEY WORDS: hypercholesterolemia; cardiovascular diseases; practice guidelines; hydroxymethylglutaryl-CoA reductase inhibitors.

DOI: $10.1111 /$ j. 1525-1497.2006.00323.x

J GEN INTERN MED 2006; 21:171-176.

$\mathrm{E}$ levated low-density lipoprotein cholesterol (LDL-C) is a major modifiable cause of coronary heart disease (CHD). The National Cholesterol Education Program (NCEP) periodically releases reports by its Adult Treatment Panel (ATP) providing recommendations for managing high blood cholesterol

Dr. Lloyd-Jones has received honoraria from Pfizer for speaking and for being a member of an advisory board.

Presented in part at the Society of General Internal Medicine National Meeting, May 14, 2005.

Address correspondence and requests for reprints to Dr. Persell: Division of General Internal Medicine, Northwestern University, 676 N. St. Clair Street, Suite 200, Chicago, IL 60611-2927 (e-mail: spersell @nmff.org). in adults. Since the 1993 ATP II guideline, ${ }^{1}$ multiple clinical trials have demonstrated the benefits of LDL-C lowering in individuals at increased risk for CHD across a range of initial cholesterol levels. ${ }^{2-15}$ Cholesterol lowering in adults with low short-term risk has not been well studied.

The 2001 ATP guideline increased the number of individuals considered to be high risk. ${ }^{16,17}$ It also recommended using cholesterol-lowering medication in adults at moderately high risk of CHD with LDL-C levels above $130 \mathrm{mg} / \mathrm{dL}$ and to consider the option of using medication in low-risk adults with LDL-C levels between 160 and $189 \mathrm{mg} / \mathrm{dL}$ or high-risk adults with LDL-C levels between 100 and $129 \mathrm{mg} / \mathrm{dL}$. Further optional modifications to the ATP III guideline, released by the NCEP in 2004, gave clinicians the choice of pursuing very low $(<70 \mathrm{mg} / \mathrm{dL})$ LDL-C levels for very high-risk adults and low $(<100 \mathrm{mg} / \mathrm{dL})$ LDL-C levels for moderately high-risk adults through using cholesterol-lowering medications and intensified lifestyle modifications (Table 1 ). ${ }^{18}$

We sought to determine the implications of these guideline changes for the U.S. population. Our primary goal was to determine the proportion of adults with LDL-C levels exceeding the ATP recommended and optional goals published in 2001 and 2004, and to estimate the number of adults exceeding the threshold to use cholesterol-lowering medication according to the 2001, optional 2001, and optional 2004 targets. Our secondary goal was to determine the magnitude of LDL-C reduction required to reach 2001 and 2004 NCEP goals for U.S. adults not on cholesterol-lowering therapy.

\section{METHODS}

\section{Study Population}

The National Health and Nutrition Examination Survey (NHANES) conducted from 1999 to 2002 recruited a nationally representative sample of the noninstitutionalized U.S. population for a home interview, physical examination, and laboratory testing. The institutional review board of the $\mathrm{Na}-$ tional Center for Health Statistics approved the survey, and participants provided informed consent. ${ }^{19}$

We included nonpregnant morning exam participants aged 20 to 79 years old $(n=4,044)$. We excluded participants who had fasted fewer than 8 or more than 24 hours, $(n=524)$, had serum triglyceride levels exceeding $400 \mathrm{mg} / \mathrm{dL}(n=106)$, did not have cholesterol measured $(n=67)$, or for whom cor-

Manuscript received June 29, 2005

Initial editorial decision September 28, 2005

Final acceptance September 29, 2005 
Table 1. Summary of National Cholesterol Education Program (NCEP) Adult Treatment Panel (ATP) Guidelines

\begin{tabular}{|c|c|c|c|}
\hline & $\begin{array}{l}\text { ATP III } \\
(2001)^{16}\end{array}$ & $\begin{array}{l}\text { ATP III Optional Goals } \\
(2001)^{16}\end{array}$ & $\begin{array}{l}\text { NCEP Optional Goals } \\
(2004)^{18}\end{array}$ \\
\hline \multicolumn{4}{|l|}{ LDL-C goal (mg/dL) } \\
\hline$\geq 2 \mathrm{RF}^{*}$ and $10 \mathrm{y}$ risk $<10 \%{ }^{\dagger}$ & $<130$ & - & - \\
\hline$\geq 2 \mathrm{RF}^{*}$ and $10 \mathrm{y}$ risk $10 \%$ to $20 \%$ & $<130$ & - & $<100$ \\
\hline $\begin{array}{l}\geq 2 \mathrm{RF}^{*} \text { and } 10 \mathrm{y} \text { risk }>20 \% \text { or } \mathrm{CHD}, \mathrm{DM} \text {, or other symptomatic } \\
\text { atherosclerosis }\end{array}$ & $<100$ & - & $<70$ \\
\hline$\geq 2 \mathrm{RF}^{*}$ and $10 \mathrm{y}$ risk $<10 \%{ }^{\dagger}$ & $\geq 160$ & - & - \\
\hline$\geq 2 \mathrm{RF}^{*}$ and $10 \mathrm{y}$ risk $10 \%$ to $20 \%$ & $\geq 130$ & - & $\geq 100$ \\
\hline $\begin{array}{l}\geq 2 \mathrm{RF}^{*} \text { and } 10 \mathrm{y} \text { risk }>20 \% \text { or } \mathrm{CHD}, \mathrm{DM} \text {, or other symptomatic } \\
\text { atherosclerosis }\end{array}$ & $\geq 130$ & $\geq 100$ & $\geq 70$ \\
\hline
\end{tabular}

${ }^{*}$ ATP III risk factors $=$ male $\geq 45$ years, female $\geq 55$ years, family history premature CHD in first-degree relative ( $<55$ years if male, $<65$ years iffemale), current cigarette smoking, hypertension, $H D L<40$. HDL $\geq 60$ counts as a negative risk factor.

${ }^{\dagger}$ Estimated 10-year risk of fatal heart disease or nonfatal myocardial infarction using the ATP III method based on the Framingham Heart Study. ${ }^{16}$

LDL-C, low-density lipoprotein cholesterol; RF, risk factor; CHD, coronary heart disease; DM, diabetes mellitus.

onary risk assessment could not be performed because of missing blood pressure information $(n=66)$.

\section{Study Variables}

We classified participants' coronary risk and LDL-C goals according to the NCEP ATP III criteria (Table 1) that defined 4 risk groups. Subjects with CHD (including self-reported prior myocardial infarction or angina) were classified as high risk. Individuals with other conditions considered to carry high CHD risk-i.e., prior stroke, peripheral arterial disease (based on an ankle brachial index $<0.9$ or a lower extremity amputation), or diabetes (self-reported physician-diagnosed diabetes or fasting glucose $\geq 126 \mathrm{mg} / \mathrm{dL}$ )-were also classified as high risk. For individuals with 2 or more risk factors-male $\geq 45$ years old, female $\geq 55$ years old, a first-degree relative with CHD before age 55 years if male or 65 years if female (only data for parents and siblings with myocardial infarction or angina before age 50 years were available), cigarette smoking, hypertension ( $\geq 140 / 90 \mathrm{~mm} \mathrm{Hg}$ or taking antihypertensive medication), or serum high-density lipoprotein cholesterol (HDL-C) $<40 \mathrm{mg} / \mathrm{dL}$ - the 10 -year risk of fatal CHD or nonfatal myocardial infarction was determined using a multivariable risk assessment tool derived from Framingham Heart Study. Individuals were then classified into 1 of 3 risk groups depending on their estimated 10-year risk of fatal CHD or nonfatal myocardial infarction ( $<10 \%$ [moderate], $10 \%$ to $20 \%$ [moderately high], or $>20 \%$ [high]). Those with fewer than 2 risk factors were assigned to the lowest-risk group. The number of risk factors was reduced by 1 if the HDL-C level was $\geq 60 \mathrm{mg} / \mathrm{dL}^{16}$

\section{LDL-Cholesterol Levels Above Guideline Goals and Thresholds for Drug Therapy}

We calculated LDL-C levels from total serum cholesterol, HDL$\mathrm{C}$, and triglyceride levels using the Friedewald equation. ${ }^{20} \mathrm{We}$ determined the proportion of adults aged 20 to 79 years exceeding LDL-C goals from 2001 and optional goals from 2004. We also calculated the proportions exceeding 2001 guideline thresholds to use medical therapy, based on the 2001 guidelines and the 2001 and 2004 optional guidelines (Table 1). ${ }^{16,18}$

\section{Sensitivity Analysis Using U.S. Preventive Services Task Force Screening Recommendations}

The 2001 U.S. Preventive Services Task Force recommendations did not advocate screening men aged 20 to 34 years and women 20 to 44 years without CHD, peripheral arterial disease, stroke, diabetes mellitus, a family history of premature CHD, or multiple CHD risk factors. ${ }^{21}$ We determined the effect of applying these guidelines on the proportion of the population exceeding NCEP guideline goals.

\section{Data Analysis}

We used SAS release 9.1 (SAS Institute Inc., Cary, NC) and SUDAAN release 9.0.1 (Research Triangle Institute, Research Triangle Park, NC) to account for the survey design and provide nationally representative proportions and accurate confidence intervals. All proportions reflect the survey weights. We used the $\chi^{2}$ test to compare categorical variables and the $t$-test for continuous variables. Significance tests were 2 -sided with a $P$ value set at $<.05$.

We used the sampling weights (which account for the probability of selection and nonresponse) to estimate the number of noninstitutionalized nonpregnant adults aged 20 to 79 years in the U.S. population in the year 2000 in each group.

\section{RESULTS}

In total, 3,281 individuals (representing 175,600,000 U.S. adults) participated in a morning examination and had no exclusion criteria. The median age was 43.0 years and $50.7 \%$ were women (Table 2). Age, sex, race/ethnicity, income, and cholesterol-lowering medication use did not differ significantly between excluded and included subjects. The included sample was representative of $94.1 \%$ of the nonpregnant U.S. population 20 to 79 years old.

\section{LDL-Cholesterol Levels Exceeding NCEP Guidelines}

According to the 2001 ATP III guideline, 1,063 (30.0\% [95\% CI, $28.0 \%$ to $32.0 \%]$ ]) exceeded their LDL-C goal. Among high-risk individuals, 476 (71.8\% [95\% CI, 67.5\% to $75.8 \%$ ]) exceeded 
Table 2. Characteristics of 3,281 Eligible NHANES 1999 to 2002 Participants*

\begin{tabular}{|c|c|}
\hline \multicolumn{2}{|l|}{ Characteristic } \\
\hline Age, $y$, median (25th to 75 th percentiles) & 43.0 (31.9 to 55.3$)$ \\
\hline Female sex, \% (95\% CI) & 50.7 (49.0 to 52.3 ) \\
\hline \multicolumn{2}{|l|}{ Race/ethnicity, \% (95\% CI) } \\
\hline White, non-Hispanic & 72.7 (68.3 to 76.8$)$ \\
\hline Black, non-Hispanic & $10.6(8.2$ to 13.7$)$ \\
\hline Mexican American & 6.9 (5.3 to 9.0$)$ \\
\hline Other & $9.7(6.5$ to 14.4$)$ \\
\hline \multicolumn{2}{|l|}{ Hypertension, \% (95\% CI) } \\
\hline Undiagnosed & $9.2(8.0$ to 10.4$)$ \\
\hline Diagnosed & 21.1 (19.2 to 23.2$)$ \\
\hline Medication for hypertension & $16.5(14.5$ to 18.8$)$ \\
\hline \multicolumn{2}{|l|}{ Diabetes, \% (95\% CI) } \\
\hline Undiagnosed & $2.4(1.8$ to 3.1$)$ \\
\hline Diagnosed & $6.9(5.7$ to 8.2$)$ \\
\hline \multicolumn{2}{|l|}{ Hypercholesterolemia, \% (95\% CI) } \\
\hline Diagnosed & $26.2(23.8$ to 28.7$)$ \\
\hline Medication for cholesterol & 9.0 (7.6 to 10.6$)$ \\
\hline Current cigarette smoker, \% (95\% CI) & 24.8 (22.2 to 27.6$)$ \\
\hline $\begin{array}{l}\text { Parent or sibling with premature coronary } \\
\text { heart disease, } \%(95 \% \mathrm{CI})\end{array}$ & $2.2(1.8$ to 2.8$)$ \\
\hline Cardiovascular disease, \% (95\% CI) & 7.8 (6.5 to 9.3$)$ \\
\hline Diagnosed coronary heart disease & $5.1(4.2$ to 6.3$)$ \\
\hline Diagnosed stroke & $1.7(1.2$ to 2.5$)$ \\
\hline Peripheral arterial disease $^{\dagger}$ & $2.4(1.9$ to 3.1$)$ \\
\hline $\begin{array}{l}\text { Total cholesterol, mg/dL, median } \\
\text { (25th to } 75 \text { th percentiles) }\end{array}$ & 196.9 (173.4 to 223.3$)$ \\
\hline $\begin{array}{l}\text { Low-density lipoprotein cholesterol, mg/dL, } \\
\text { median (25th to } 75 \text { th percentiles) }\end{array}$ & 120.1 (97.9 to 143.9 ) \\
\hline $\begin{array}{l}\text { High-density lipoprotein cholesterol, mg/dL, } \\
\text { median (25th to 75th percentiles) }\end{array}$ & 47.4 (39.9 to 58.7$)$ \\
\hline
\end{tabular}

*Data are weighted to the corresponding portion of the U.S. population. ${ }^{\dagger}$ Ankle brachial index $<0.9$ or lower extremity amputation.

NHANES, National Health and Nutrition Examination Survey; CI, confidence interval; NCEP, National Cholesterol Education Program; RF, risk factor; CVD, cardiovascular disease.

the 2001 target LDL-C level of $<100 \mathrm{mg} / \mathrm{dL}$. Among all participants, 534 (14.2\% [95\% CI, 12.7\% to 15.8\%]) exceeded the ATP III threshold for medication. In the 2001 ATP III guideline, medication use was considered optional for 2 groups: lowrisk persons with LDL-C levels between 160 and $189 \mathrm{mg} / \mathrm{dL}$ and high-risk persons with LDL-C levels between 100 and $129 \mathrm{mg} / \mathrm{dL}$. When we included persons in these 2 groups as being eligible for medications, 951 (26.3\% [95\% CI, $24.1 \%$ to $28.6 \%$ ]) were above the threshold to use medication (Table 3 ).

The optional 2004 NCEP goals and thresholds for drug therapy include an LDL-C $<100 \mathrm{mg} / \mathrm{dL}$ for moderately high- risk adults and $<70 \mathrm{mg} / \mathrm{dL}$ for high-risk adults (Table 1). By these criteria, 1,293 (35.8\% [95\% CI, 33.8 to 37.9]) were above their goal and 1,181 (32.2\% [95\% CI, 29.9 to 34.5]) were above the threshold for drug therapy. Nearly everyone in the 2 highest risk groups exceeded their optional LDL-C goal (Table 3).

\section{Analysis Using U.S. Preventive Services Task Force Screening Recommendations}

When we examined only individuals who would be screened according to the U.S. Preventive Services Task Force (USPSTF) recommendations, the population estimates for the number of 20- to 79-year-old U.S. adults exceeding NCEP goals decreased. The proportion exceeding their ATP III LDL-C goal fell from $30.0 \%$ to $25.8 \%$ and the proportion exceeding optional thresholds for drug therapy fell from $26.3 \%$ to $23.2 \%$. The proportion of adults exceeding optional 2004 NCEP LDL-C goals fell from $35.8 \%$ to $31.7 \%$ and the proportion exceeding the optional NCEP 2004 thresholds for drug therapy fell from $32.2 \%$ to $29.1 \%$. Most $(88.8 \%)$ persons for whom the USPSTF who would recommend no screening had LDL-C levels at ATP III goals, 97.3\% had levels below the ATP III threshold for drug therapy, and $91.7 \%$ were below the optional ATP III thresholds for drug therapy.

\section{Use of Cholesterol-Lowering Medications and LDL- C Control}

Among adults aged 20 to 79 years old, 306 (9.0\% [95\% CI, 7.6 to 10.6]) used cholesterol-lowering medication. By ATP III risk groups, $3.5 \%$ (95\% CI, $2.6 \%$ to $4.8 \%$ ) of the lowest risk group, $7.7 \%$ (95\% CI, $4.65 \%$ to $12.34 \%$ ) of the moderate-risk group, $15.7 \%$ (95\% CI, $11.18 \%$ to $21.6 \%$ ) of the moderately high-risk group, and $28.6 \%$ (95\% CI, $24.25 \%$ to $33.27 \%$ ) of the high-risk group used cholesterol-lowering medication. Of medication users, 285 (92.6\% [95\% CI, 88.9\% to 95.2\%]) used a statin, and only $14(5.2 \%$ [95\% CI, $2.4 \%$ to $11.0 \%])$ used more than 1 kind of cholesterol-lowering medication. Among medication users, 124 (41.8\% [95\% CI, 35.0\% to 48.8\%]) exceeded their ATP III LDL-C goals, and 195 (63.7\% [95\% CI, 57.2\% to 69.7\%]) exceeded the optional 2004 NCEP goals.

\section{LDL-C Reduction Needed for Adults Not Already on Drug Therapy}

Of the population not currently using cholesterol-lowering therapy, 538 (15.6\% [95\% CI, 13.6\% to $17.7 \%]$ ) exceeded their

Table 3. Population Estimates and Frequencies of Low-Density Lipoprotein Cholesterol (LDL-C) Levels Exceeding Guideline Goals Among Adults Aged 20 to 79 years*

\begin{tabular}{|c|c|c|c|c|c|}
\hline \multirow[b]{2}{*}{ Risk group } & \multicolumn{5}{|c|}{ Adult Treatment Panel III Risk Categories Population Estimate in Millions (\%) } \\
\hline & Total & Lower & Moderate & Moderately high & High \\
\hline Study participants & 3,281 & 1,946 & 395 & 285 & 655 \\
\hline Population estimate (millions) & 175.7 & 112.6 & 22.6 & 11.9 & 29.6 \\
\hline \multicolumn{6}{|l|}{ Guideline } \\
\hline \multicolumn{6}{|l|}{ Adult Treatment Panel III (2001) ${ }^{10}$} \\
\hline Above LDL-C goal & $52.6(30.0)$ & $15.1(13.4)$ & $10.0(44.2)$ & $7.0(58.8)$ & $20.6(71.8)$ \\
\hline Above threshold for medication & $24.9(14.2)$ & $3.5(3.1)$ & $3.6(15.7)$ & $7.0(58.8)$ & $10.9(38.1)$ \\
\hline Above optional threshold for medication & $46.2(26.3)$ & $15.1(13.4)$ & $3.6(15.7)$ & $7.0(58.8)$ & $20.6(71.8)$ \\
\hline \multicolumn{6}{|l|}{ NCEP optional goals $(2004)^{14}$} \\
\hline Above optional LDL-C goal & $62.9(35.8)$ & $15.1(13.4)$ & $10.0(44.2)$ & $10.4(87.4)$ & $27.5(96.0)$ \\
\hline Above optional threshold for medication & $56.5(32.2)$ & $15.1(13.4)$ & $3.6(15.7)$ & $10.4(87.4)$ & $27.5(96.0)$ \\
\hline
\end{tabular}

*Numbers represent the estimated size of the corresponding portion of the U.S. adult population from which the sample was drawn. 
Table 4. Distribution of LDL-C Above ATP III (2001) and Optional (2004) National Cholesterol Education Program Goals for Persons Not Using Cholesterol-Lowering Medication, By Risk Group, Estimated Population Size in Millions (\%)

\begin{tabular}{|c|c|c|c|c|c|}
\hline Risk Group & LDL-C Goal (mg/dL) & At Goal & $\leq 10 \%$ Above Goal & $11 \%$ to $40 \%$ Above Goal & $>40 \%$ Above Goal \\
\hline Lower & $<160$ & $94.3(86.8)$ & $8.4(7.7)$ & $5.5(5.1)$ & $0.4(0.4)$ \\
\hline Moderate & $<130$ & $11.1(53.3)$ & $3.8(18.2)$ & $5.8(28.0)$ & $0.09(0.4)$ \\
\hline \multirow[t]{2}{*}{ Moderately high } & $<130^{*}$ & $3.9(39.1)$ & $2.6(25.7)$ & $3.5(34.7)$ & $0.05(0.5)$ \\
\hline & $<100^{\dagger}$ & $1.2(12.3)$ & $0.6(6.2)$ & $6.9(68.7)$ & $1.3(12.9)$ \\
\hline \multirow[t]{2}{*}{ High } & $<100^{*}$ & $4.6(22.3)$ & $2.7(13.2)$ & $10.1(49.2)$ & $3.1(15.4)$ \\
\hline & $<70^{\dagger}$ & $0.4(1.8)$ & $0.5(2.6)$ & $7.6(37.1)$ & $12.0(58.5)$ \\
\hline
\end{tabular}

*ATP III (2001) goals.

Optional (2004) NCEP goals.

LDL-C, low-density lipoprotein cholesterol; ATP, Adult Treatment Panel.

ATP III LDL-C target by $11 \%$ to $40 \%$. Few people $(2.3 \%$ [95\% CI, $1.7 \%$ to $3.2 \%$ ]) required more than a $40 \%$ reduction in their LDL-C level to achieve their ATP III goal. However, if the optional 2004 goals were widely applied, 528 (16.2\% [95\% CI, $14.7 \%$ to $17.7 \%$ ]) would require an $11 \%$ to $40 \%$ reduction and 339 (8.6\% [95\% CI, $7.4 \%$ to $9.9 \%$ ) would require more than a $40 \%$ LDL-C reduction to reach their optional goal. The extent of LDL-C reduction required to reach goal stratified by risk group is shown in Table 4.

\section{DISCUSSION}

We used data from 3,281 participants of the 1999 to 2002 NHANES to assess the implications of widely applying NCEP recommendations and optional thresholds. Thirty percent of the U.S. adult population had LDL-C levels exceeding ATP III goals. Furthermore, $18 \%$ of individuals not taking drug therapy exceeded their LDL-C goal by more than $10 \%$ and thus would be unlikely to reach their LDL-C target without pharmacotherapy or highly specialized diets. ${ }^{21-26}$ Medications to lower cholesterol were underused, especially among individuals at increased short-term risk for CHD.

Our results demonstrate the impact that recent NCEP guideline changes could have on the number of individuals exceeding LDL-C goals if these recommendations were fully implemented in clinical practice. If the optional NCEP goals described in 2004 were widely adopted, 52.9 million adults (30\%) not currently on medication would exceed their optional LDL-C goal, and 40 million (25\%) would be more than $10 \%$ above their goal. Restricting the population screened for lipid disorders to exclude younger, low-risk individuals as described by the USPSTF guideline ${ }^{27}$ only moderately reduced the number of U.S. adults with LDL-C levels exceeding NCEP goals.

Among adults at moderately high or high cardiovascular risk, most (68\%) exceed the LDL-C goal recommended by the ATP III report. Adopting the lower optional targets would mean nearly all persons in these risk groups would have LDL-C levels exceeding their goals, despite the fact that $25 \%$ of this population already used cholesterol-lowering medication.

The downward shifts in LDL-C targets raise the proportion of adults requiring intermediate (11\% to $40 \%)$ and large $(>40 \%)$ reductions to achieve their target levels. The optional 2004 NCEP goals increased the proportion of the untreated 20to 79 -year-old population needing more than a $40 \%$ reduction in their LDL-C to $8.6 \%$. For some people, maximizing therapeutic lifestyle changes and using standard dosages of statins would suffice to achieve these goals. However, many persons will be unable to reach newer optional targets using 1 of the therapeutic regimens tested in the long-term clinical trials of statins. ${ }^{2-6,9-11,14}$ High doses of potent statins (atorvastatin $80 \mathrm{mg}$ or simvastatin $80 \mathrm{mg}$ daily) that reduce LDL-C by more than $40 \%$ have been tested for up to 2 years in very high-risk populations. ${ }^{7,8,12,13,15}$ Since the publication of the 2004 NCEP update, the safety of atorvastain $80 \mathrm{mg}$ daily for up to 5 years was demonstrated in 5,000 persons under 76 years of age with stable CHD. ${ }^{15}$ Evidence of long-term safety of the potent rosuvastatin is not yet available. Widespread use of high-dose statin therapy could lead to higher rates of adverse effects such as rhabdomyolysis if individuals who were excluded from most clinical trials (i.e., the elderly, individuals with renal or hepatic impairment or who use medications that interact with statins) are exposed to high-dose statins in real-world settings. ${ }^{28}$

The authors of the 2004 NCEP report acknowledge that optional LDL-C goals may be out of reach for some patients given the limitations of currently available lipid-lowering agents, and their recommendations allow for individualized clinical judgment. ${ }^{18}$ For many patients, the decision will be whether to use well-tested medications at dosages that have proven clinical benefits but cannot achieve the optional NCEP LDL-C goals, or to use drugs in combination or at higher doses. High-dose statin therapy or combination drug therapy (such as combining a statin with a bile acid sequestrant, niacin, a fibric acid derivative, and/or ezetimibe) may enable some additional individuals to achieve lower LDL-C goals but these options are likely to come at greater expense and have less long-term safety and efficacy data to support their use. Future studies should assess the long-term risks and benefits of combination cholesterol-lowering medical therapy and to determine whether combination or single drug treatment is preferred for high- and intermediate-risk individuals.

The 2001 and 2004 ATP reports have major economic ramifications. The expense of statins has been implicated in their underuse by Medicare beneficiaries with $\mathrm{CHD} .{ }^{29}$ Without cost reductions, purchasing standard-dose statin therapy ${ }^{18}$ for the 25 million people in the U.S. who exceed the ATP III threshold for drug therapy could be prohibitively expensive. At current retail prices, a year's supply of generic lovastatin $40 \mathrm{mg}$ daily can cost at least $\$ 450$ to $\$ 700$. For the nearly 40 million people not currently using cholesterol-lowering medication who exceed their optional NCEP 2004 goals by more than $10 \%$, drug treatment could cost $\$ 18$ billion annually. Using name-brand statins would raise this estimate 3 - to 4fold. ${ }^{30}$ Using high-dose statin and combination drug therapy would increase costs further. Greater availability of generic statins, group purchasing, or other cost reducing measures 
may enable more individuals to benefit from cholesterol-lowering therapy. Furthermore, much of the cost of cholesterol treatment for high-risk individuals may be offset by reductions in the direct and indirect cost of CHD; for some high-risk subgroups, drug therapy to lower cholesterol may even be costsaving. ${ }^{31,32}$

The ATP III recommendation to consider medication use for adults with fewer than 2 concomitant risk factors and an LDL-C level between 160 and $189 \mathrm{mg} / \mathrm{dL}$ (6.6\% of adults) warrants comment. These individuals have lower short-term CHD risk than the participants in primary prevention trials who were middle-aged and had other risk factors such as hypertension, current smoking, or low HDL-C. ${ }^{3,6,7}$ The cost-effectiveness of using cholesterol-lowering drug treatment depends on treatment costs, the population's CHD and stroke risk, and the age of the population (for persons with similar CHD risk, cholesterol lowering is more cost effective for younger adults). ${ }^{21}$ For persons in this optional ATP III treatment group with LDL-C levels between 160 and $189 \mathrm{mg} / \mathrm{dL}$, the 10 -year CHD risk is low (approximately 2\%). If statin therapy is assumed to reduce the CHD event rate by 30\%, 1,670 personyears of treatment would be required to prevent $1 \mathrm{CHD}$ event. At $\$ 450$ per person per year, the medication costs to prevent this event would be at least $\$ 750,000$ and subsequent office visits and monitoring would raise costs further. While a formal cost-effectiveness analysis is beyond the scope of our investigation, we believe that treating people in this low-risk group with cholesterol-lowering medication is unlikely to be cost effective at current statin prices.

Our study has several limitations. The number of individuals studied was modest. While our findings are generally in accord with analyses performed with the larger NHANES sample from 1988 to $1994,{ }^{33}$ we could not accurately estimate the size of some population subgroups. Results from this survey are weighted to account for the chance of selection, nonparticipation, and excluding nonfasting persons; however, our findings might be less generalizable if excluded persons or nonparticipants had fasting LDL-C levels substantially different from study participants. Our population estimates of the number of adults with LDL-C levels exceeding goals may be underestimates for several reasons. We did not account for the proportion of the population represented by the $5.9 \%$ of the sample meeting exclusion criteria. In addition, we did not estimate the number of adults 80 years and older who may be eligible for cholesterol-lowering therapy. ${ }^{9}$ We likely underestimated the proportion of adults with LDL-C levels above guideline goals because we may have classified some of the subgroup using cholesterol-lowering medication as lower risk when their pretreatment lipoprotein values would have placed them in a higher risk group. We did not have a precise measure of atherosclerotic cerebrovascular disease. We may have misclassified some patients with carotid atherosclerosis as lower risk, and may have misclassified some subjects with nonatheroembolic strokes as high risk. Lastly, we may have misclassified the risk group for some individuals because the medical and family history data were self-reported.

In summary, many U.S. adults, especially those at increased cardiovascular risk, have uncontrolled LDL-cholesterol by 2001 ATP III guidelines. Optional LDL-C targets from 2004 greatly increased the number of individuals for whom drug therapy may be needed to reach therapeutic targets. A substantial number of people are unlikely to achieve optional
NCEP LDL-C goals with standard-dose statins. Current costs of these drugs may place them out of reach for many patients likely to benefit from them. Research is needed to define longterm risks, benefits, and cost-effectiveness of combination cholesterol-lowering drug therapy compared with high-dose statin therapy alone.

This study was financially supported by the Division of General Internal Medicine funds, Northwestern University.

\section{REFERENCES}

1. Expert Panel on Detection, Evaluation, and Treatment of High Blood Pressure in Adults. Summary of the second report of the National Cholesterol Education Program (NCEP) Expert Panel on Detection, Evaluation, and Treatment of High Blood Cholesterol in Adults (Adult Treatment Panel II). JAMA. 1993;269:3015-23.

2. Scandanavian Simvastatin Survival Study Group. Randomised trial of cholesterol lowering in 4444 patients with coronary heart disease: the Scandinavian Simvastatin Survival Study (4S). Lancet. 1994; 344:1383-9.

3. Shepherd J, Cobbe SM, Ford I, et al. Prevention of coronary heart disease with pravastatin in men with hypercholesterolemia. West of Scotland Coronary Prevention Study Group. N Engl J Med. 1995;333: 1301-7.

4. Sacks FM, Pfeffer MA, Moye LA, et al. The effect of pravastatin on coronary events after myocardial infarction in patients with average cholesterol levels. Cholesterol and Recurrent Events Trial investigators. N Engl J Med. 1996;335:1001-9.

5. The long-Term Intervention with Pravastatin in Schemic Disease (LIPID) Study Group. Prevention of cardiovascular events and death with pravastatin in patients with coronary heart disease and a broad range of initial cholesterol levels. The Long-Term Intervention with Pravastatin in Ischaemic Disease (LIPID) Study Group. N Engl J Med. 1998;339:1349-57.

6. Downs JR, Clearfield M, Weis S, et al. Primary prevention of acute coronary events with lovastatin in men and women with average cholesterol levels: results of AFCAPS/TexCAPS. Air Force/Texas Coronary Atherosclerosis Prevention Study. JAMA. 1998;279:1615-22.

7. Pitt B, Waters D, Brown WV, et al. Aggressive lipid-lowering therapy compared with angioplasty in stable coronary artery disease. atorvastatin versus revascularization treatment investigators. N Engl J Med. 1999;341:70-6.

8. Schwartz GG, Olsson AG, Ezekowitz MD, et al. Effects of atorvastatin on early recurrent ischemic events in acute coronary syndromes: the MIRACL study: a randomized controlled trial. JAMA. 2001;285:1711-8.

9. Shepherd J, Blauw GJ, Murphy MB, et al. Pravastatin in elderly individuals at risk of vascular disease (PROSPER): a randomised controlled trial. Lancet. 2002;360:1623-30.

10. Heart Protection Study Collaborative Group. MRC/BHF heart protection study of cholesterol lowering with simvastatin in 20,536 highrisk individuals: a randomised placebo-controlled trial. Lancet. 2002; 360:7-22.

11. Sever PS, Dahlof B, Poulter NR, et al. Prevention of coronary and stroke events with atorvastatin in hypertensive patients who have average or lower-than-average cholesterol concentrations, in the Anglo-Scandinavian Cardiac Outcomes Trial-Lipid Lowering Arm (ASCOT-LLA): a multicentre randomised controlled trial. Lancet. 2003;361:1149-58.

12. Cannon CP, Braunwald E, McCabe $\mathbf{C H}$, et al. Intensive versus moderate lipid lowering with statins after acute coronary syndromes. N Engl J Med. 2004;350: 1495-504.

13. de Lemos JA, Blazing MA, Wiviott SD, et al. Early intensive vs a delayed conservative simvastatin strategy in patients with acute coronary syndromes: phase $Z$ of the A to $Z$ trial. JAMA. 2004;292:1307-16.

14. Colhoun HM, Betteridge DJ, Durrington PN, et al. Primary prevention of cardiovascular disease with atorvastatin in type 2 diabetes in the Collaborative Atorvastatin Diabetes Study (CARDS): multicentre randomised placebo-controlled trial. Lancet. 2004;364:685-96.

15. LaRosa JC, Grundy SM, Waters DD, et al. Intensive lipid lowering with atorvastatin in patients with stable coronary disease. N Engl J Med. 2005;352:1425-35. 
16. Executive Summary of the Third Report of the National Cholesterol Education Program (NCEP) Expert Panel on Detection, Evaluation, and Treatment of High Blood Cholesterol in Adults (Adult Treatment Panel III). JAMA. 2001;285:2486-97.

17. Expert Panel on Detection, Evaluation, and Treatment of High Blood Pressure in Adults. Third Report of the National Cholesterol Education Program (NCEP) Expert Panel on Detection, Evaluation, and Treatment of High Blood Cholesterol in Adults (Adult Treatment Panel III) final report. Circulation. 2002;106:3143-421.

18. Grundy SM, Cleeman JI, Merz CN, et al. Implications of recent clinical trials for the National Cholesterol Education Program Adult Treatment Panel III guidelines. Circulation. 2004;110:227-39.

19. National Center for Health Statistics. National Health and Nutrition Examination Survey. Available at: http://www.cdc.gov/nchs/nhanes.htm. Accessed December 6, 2004.

20. Friedewald WT, Levy RI, Fredrickson DS. Estimation of the concentration of low-density lipoprotein cholesterol in plasma, without use of the preparative ultracentrifuge. Clin Chem. 1972;18:499-502.

21. Gardner CD, Coulston A, Chatterjee L, Rigby A, Spiller G, Farquhar JW. The effect of a plant-based diet on plasma lipids in hypercholesterolemic adults: a randomized trial. Ann Intern Med. 2005;142:725-33.

22. Aldana SG, Greenlaw RL, Diehl HA, et al. Effects of an intensive diet and physical activity modification program on the health risks of adults. J Am Diet Assoc. 2005;105:371-81.

23. Yancy WS, Jr., Olsen MK, Guyton JR, Bakst RP, Westman EC. A lowcarbohydrate, ketogenic diet versus a low-fat diet to treat obesity and hyperlipidemia: a randomized, controlled trial. Ann Intern Med. 2004; 140:769-77.

24. Jenkins DJ, Kendall CW, Marchie A, et al. Effects of a dietary portfolio of cholesterol-lowering foods vs lovastatin on serum lipids and C-reactive protein. JAMA. 2003;290:502-10.
25. Raeini-Sarjaz M, Vanstone CA, Papamandjaris AA, Wykes LJ, Jones PJ. Comparison of the effect of dietary fat restriction with that of energy restriction on human lipid metabolism. Am J Clin Nutr. 2001; 73:262-7.

26. Howell WH, McNamara DJ, Tosca MA, Smith BT, Gaines JA. Plasma lipid and lipoprotein responses to dietary fat and cholesterol: a metaanalysis. Am J Clin Nutr. 1997;65:1747-64.

27. U.S. preventive services task force. Screening adults for lipid disorders: recommendations and rationale. Am J Prev Med. 2001;20(3 suppl): 73-6.

28. Graham DJ, Staffa JA, Shatin D, et al. Incidence of hospitalized rhabdomyolysis in patients treated with lipid-lowering drugs. JAMA. 2004;292:2585-90.

29. Federman AD, Adams AS, Ross-Degnan D, Soumerai SB, Ayanian JZ. Supplemental insurance and use of effective cardiovascular drugs among elderly medicare beneficiaries with coronary heart disease. JAMA. 2001;286:1732-9.

30. Based on the lowest prices reported at www.walgreens.com, www.drugstore.com and www.cvs.com. Accessed August 22, 2005.

31. Jonsson B. Economics of drug treatment: for which patients is it costeffective to lower cholesterol? Lancet. 2001;358:1251-6.

32. Prosser LA, Stinnett AA, Goldman PA, et al. Cost-effectiveness of cholesterol-lowering therapies according to selected patient characteristics. Ann Intern Med. 2000;132:769-79.

33. Fedder DO, Koro CE, L'Italien GJ. New National Cholesterol Education Program III guidelines for primary prevention lipid-lowering drug therapy: projected impact on the size, sex, and age distribution of the treatment-eligible population. Circulation. 2002;105:152-6.

34. Jacobson TA, Schein JR, Williamson A, Ballantyne CM. Maximizing the cost-effectiveness of lipid-lowering therapy. Arch Intern Med. 1998;158:1977-89. 